\title{
Evolution of southeast Australian fire activity seasons
}

\author{
$\underline{\text { R. McRae }}^{\text {a }}$ \\ ${ }^{a}$ Risk and Planning, ACT Emergency Services Agency, Canberra. \\ Email: rick.mcrae@act.gov.au
}

\begin{abstract}
It is widely reported that climate change is impacting on wildfire risks in Australia. Fire seasons are seen to be starting earlier and finishing later. Climate modelling produces equivalent changes in fire weather. However national-scale datasets on fire activity are not widely available. A number of studies have used algorithm-generated "hotspots" from the pair of MODIS sensors carried on the TERRA and AQUA satellites for over 17 years. This dataset includes all types of fire - whether planned or not, and does not pickup low intensity fire activity. It is also sensitive to cloud cover. Nevertheless, the MODIS hotspot dataset, covering 4.5 million records since July 2002 , provides a coverage that is broadly complete and consistent within those constraints. Hotspots can be classified according to geographic location and time of year. McRae \& Featherston (2015) used a technique of producing "wind roses" to show fire activity seasonality, showing relative occurrences by month. To do this hotspots were aggregated to one degree grid-cells.
\end{abstract}

In this paper hotspot "wind roses" are generated though aggregation to half-degree grid-cells over southeast Australia. To detect changes in fire activity patterns, the dataset is split into two epochs: Epoch 1 spans from July 2002 to June 2012, and Epoch 2 from July 2012 to June 2019. Impacts of climate change may be assessed through changes in key parameters of the pattern between the epochs. A number of grid-cells lack sufficient hotspots to form clear patterns. Others have fire activity through much of the year, and a seasonality pattern cannot be described. Change detection requires a defined pattern for both epochs.

The month of peak fire activity has a mix of no change, shifts to later months and shifts to earlier months. The geographic distribution of these is complex, although some regions can be identified as having uniform changes. The length of the fire activity period can be analysed in an equivalent manner. The length is identified where a single distinct peak of activity stands out from the other months. Maps of the length for both epochs were produced, as well as for the change in length. There is no evident geographic correlation between the two sets of results.

The Australian pyroCb register (McRae, et al., 2015, di Virgilio, et al., 2019) was assessed in conjunction with these patterns. PyroCbs are the most extreme and damaging form of fire behaviour, so any changes in their occurrence patterns are of concern. Given the limited dataset, there were still some regional patterns detected. It is noted that in some areas the month of peak fire activity in either Epoch is linked to extreme wildfire and pyroCb activity.

Without a clear filtering of wildfires or planned fires in the MODIS hotspot dataset it is not possible to assess trends in the timing of start or end of activity periods. Notwithstanding the constraints on the use of hotspots for this purposes, the results should form a benchmark against which to look for future changes and to validate climate model results.

Keywords: Climate change, extreme wildfires, MODIS, hotspots, pyroCb 


\section{INTRODUCTION}

Since 2002 there have been two sun-synchronous near-polar orbiting earth observations satellites carrying the Moderate Resolution Imaging Spectroradiometer (MODIS) payload. One of the design goals of MODIS was the detection of fires on the earth's surface. NASA has continuously made datasets of image pixels that satisfy an algorithm looking for excess heat - known as "hotspots" (see, for example, Giglio, 2013).

This global and continuous dataset has driven a wide range of research outcomes of immense value to fire managers.

Starting in 2011 the hotspot seasonality project has compared each year's hotspot distribution to a climatology of previous hotspots (McRae \& Featherston, 2015). For the first time, this provided a true resolution of dynamics in hotspot occurrences. Each year, after June 30th, the analysis was repeated and worked up for presentation to the fire sector's working group preparing the official southern Australian annual bushfire outlook. The results provided a verification of the previous year's outlooks and gave guidance on where the coming year might head.

Some key aspects of this are:

- Using a one-degree resolution, the continent was divided into Zones with a relatively uniformly patterned (or uniformly unpatterned) seasonality pattern. The distribution of these bore little resemblance to the standard fire season map widely used by fire agencies and fire researchers (Figure 2.5 in Luke \& McArthur, 1978)

- Hotspots include all fires - industrial fires, wildfires and hazard reduction burns. It is not practical to consistently filter them.

- The climatology was fixed, to a July 2002 to June 2012 baseline. This was important if climate change was going to influence the seasonality patterns.

- Extreme wildfire events may be confirmed by the absence of hotspots in an area known to have carried a hot fire, as there is little residual heat when the satellite eventually passes overhead.

A number of reviews (for example Williams, et al., 2009) and studies (for example Clarke \& Evans, 2017, Dowdy, et al., 2019, Harris \& Lucas, 2017 and Jain, et al., 2017) have examined trends in fire season severity, start and end. In Australia, the application for McArthur Forest Fire Danger Index over the entire continent is both unavoidable (as it is the only FDI that can be calculated from meteorological data only) and seriously flawed (most of the continent is not forested). The uncertainties around identified trends are discussed in Clarke, 2015.

Given the impact of extended response availability on the community, on fire crews and on Government contractual obligations, it is important to address the uncertainties. The MODIS dataset, indicating actual fires, has the properties to independently verify, or otherwise, meteorological analyses.

\section{METHOD}

For every MODIS hotspot the latitude, longitude and date can be readily extracted, allowing easy spatiotemporal aggregation. These were grouped into 0.5 degree pixels and into month (see Figure 1). Any finer resolution would introduce more problems and noise than the benefits due to resolution.

The MODIS climatology ten year baseline used in McRae \& Featherstone, 2015 became Epoch 1, while Epoch 2 was seven years spanning July 2012 to June 2019, inclusive. While this division is, in some ways arbitrary, its operational use makes it a useable one. The spatial domain chosen was southeast Australia - including all of NSW, Victoria, ACT and Tasmania and adjacent parts of SA and Queensland.

The "wind rose" technique of McRae \& Featherston (2015) involves drawing twelve lines from each gridcell's centroid, with the line for each month number oriented as for hours on an analog clock-face. The length of each line is proportional to the number of hotspots for that month in that grid-cell, but with the total length of the twelve lines set to a constant (see Figure 1). Thus the technique shows relative activity patterns, not absolute ones.

\section{PEAK FIRE ACTIVITY}

The results for Epoch 1 are shown in Figure 2A, those for Epoch 2 in Figure 2B. A further step allowed the mapping of the differences between the Epoch1 and Epoch 2 results, see Figure 2C. 

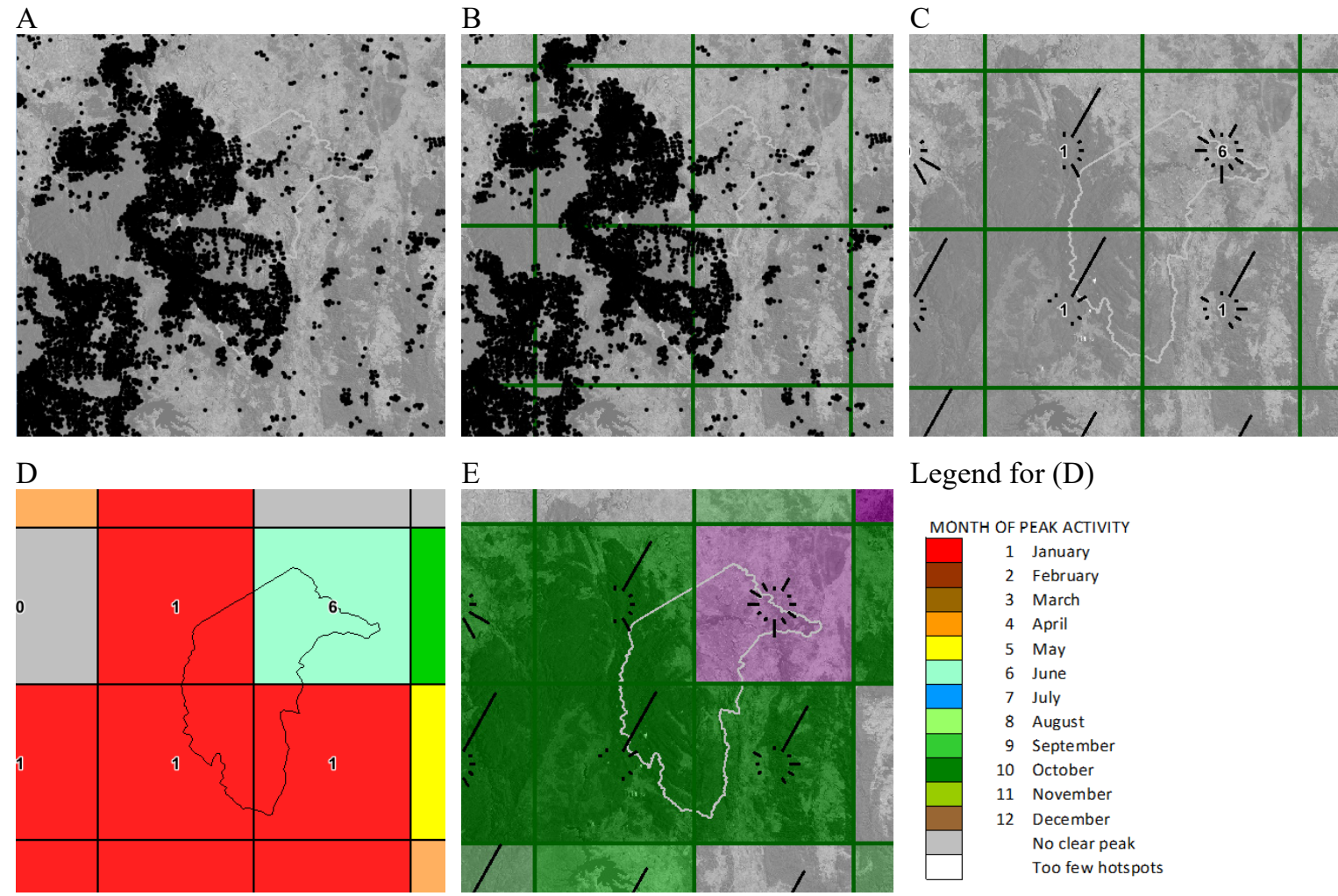

Legend for (D)

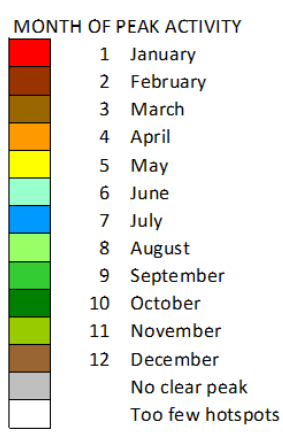

Figure 1. Data aggregation process: (A) Raw hotspots; (B) 0.5 degree pixels; (C) "Wind roses" showing relative frequency by month, with months numbered as on a clock-face and the total length of all twelve arms a constant; (D) Identification of month with peak frequency and assignment of a colour to match that, as in the legend. (E) Assessment of the drift in month of peak activity. The legend is as in Figure 2.

A

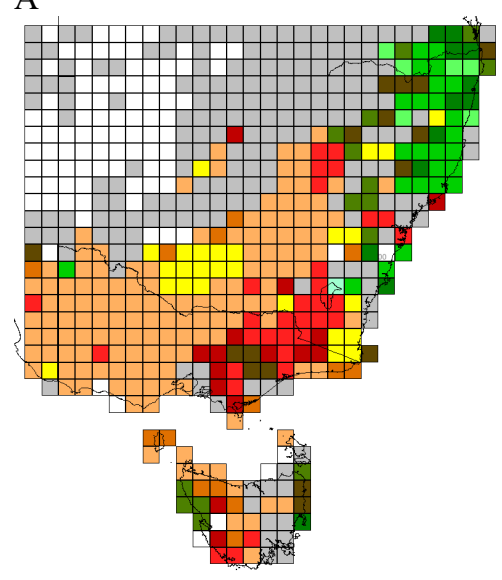

Legend for (C)

PEAK ACTIVITY:

Epoch 2 relative to Epoch 1

3 or more months later

2 months later

2 months later

No change

1 month earlie

2 months earlier

3 or more months earlier
B
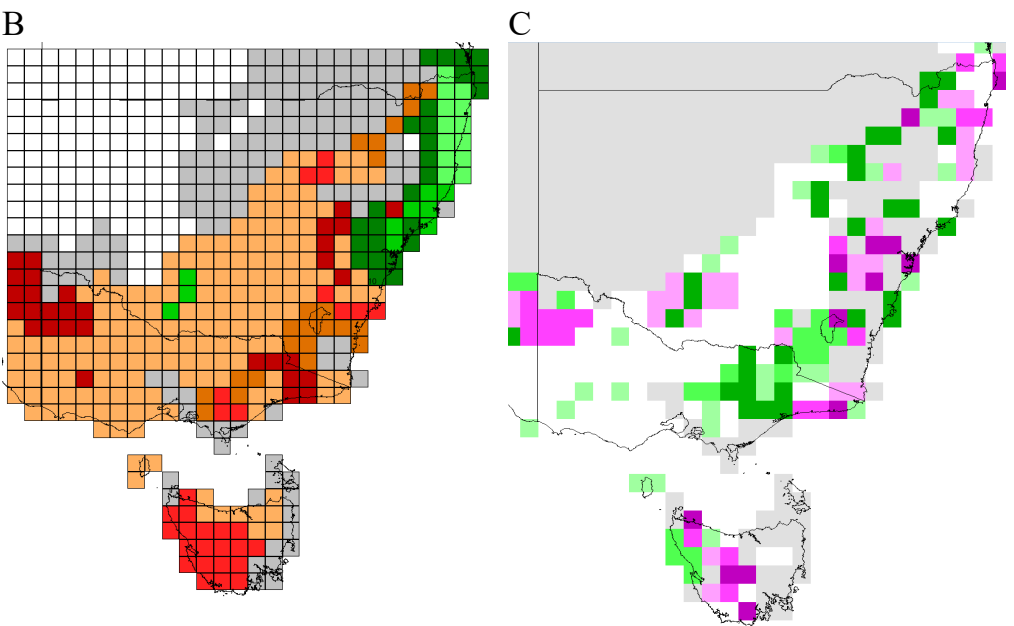

Figure 2. (A) Epoch1 peak frequency month map, using the colour scheme in Figure 1. (B) Epoch2 peak frequency month map, using the colour scheme in Figure 1. (C) Map of the difference in peak frequency month between Epochs - Epoch 2 relative to Epoch 1. Grey areas are where either Epoch lacks a clear peak. 


\section{Discussion}

A number of trends stand out.

- In terms of change of peak timing, the trend is very variable across the domain. Some consistent regions stand-out, including: central Tasmania, the Sydney Basin, and the high country between Melbourne and Canberra.

- Despite this, there has been a notable homogenisation of the wheatbelt, Tasmania and the Northern Rivers of NSW. This process could reflect extreme wildfires or deliberate management actions (a possible mechanism might be switching away from spring prescribed burning to only burning in autumn). This homogenisation may act to make fire-fighting asset sharing more problematic in the future, as wider areas have more fire at the same time.

- Patterns in the high country (including the Grampians), and trends in those patterns, are driven by occurrences of clusters of extreme wildfires (in the sense of Sharples, et al., 2018), which overwhelm all other hotspots sources.

- A number of coastal sites are aseasonal, reflecting a strong exposure to the variable effects of sea surface temperature anomalies.

- The mallee country of NW Victoria has shown a major change to a uniform summer peak. The cause of this is not evident from this data.

All of the usual caveats for using MODIS hotspot data apply here. The primary benefit from this analysis is expected to be validation of climate change modelling. It is important to note that this analysis is of observations, while climate change predictions are generally driven by numerical weather models. The assumptions and data caveats behind the two approaches are very different.

A

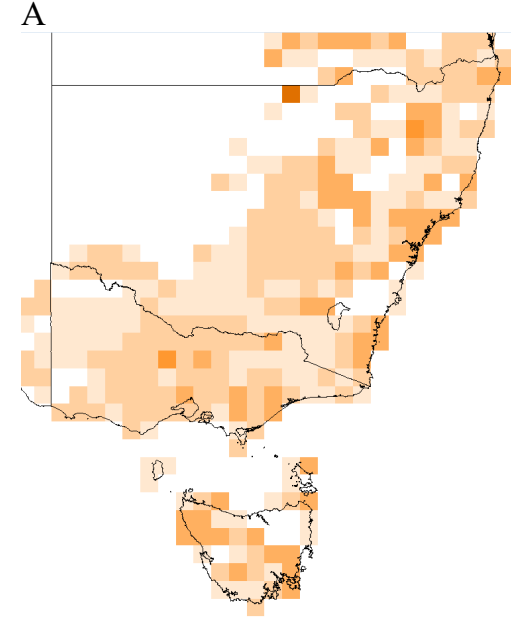

Legend for (A) \& (B)

LENG TH OF FIRE ACTIVITY PERIOC
\begin{tabular}{|l|}
$10,11,12$ months \\
8,9 months \\
$5,6,7$ months \\
3,4 months \\
1,2 months
\end{tabular}

B

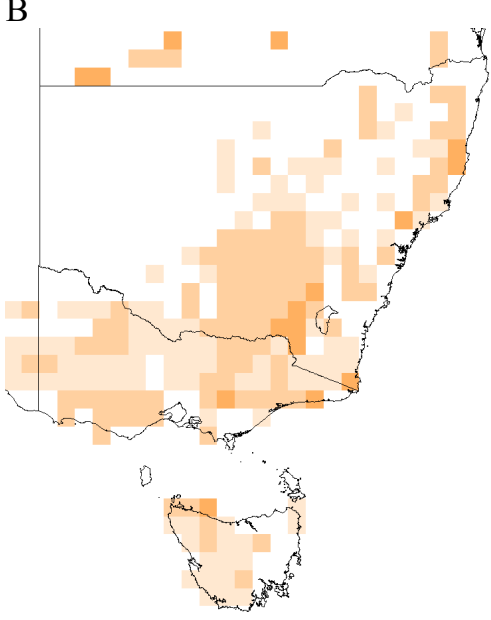

Figure 3. (A) Length of fire activity period in Epoch 1, in months. (B) Length of fire activity period in Epoch 2, in months. (C) Change in length of fire activity period between Epoch1 and Epoch 2, in months. Grey areas have insufficient fires or fire patterns to detect a drift.

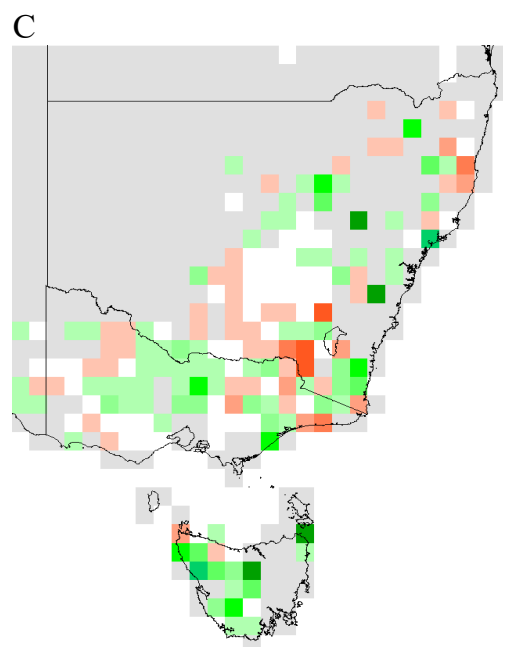

Legend for (C)

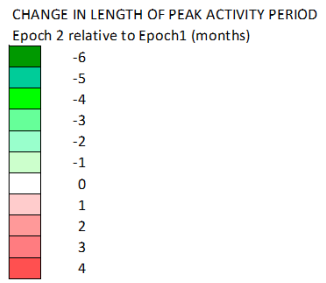

\section{LENGTH OF FIRE ACTIVITY}

Using the "wind rose" technique it is possible to detect fire seasons. This is a block of contiguous months with above average activity levels. A period of one month is allowed, while a period above 6 months is difficult to separate from average levels. Again there may be too few fires to detect a pattern. There may also be areas with two roughly equivalent peaks (most likely one from wildfires and one from prescribed burning), for which no result is recorded. 
The fire activity period length for Epoch 1 is shown in Figure 3A, while that for Epoch 2 is shown in Figure 3B. Figure 3C shows the difference between the two.

\section{Discussion}

The patterns are quite heterogeneous, making it difficult to extract conclusions. This is especially due to many areas lacking a clear fire activity period, thus preventing any change being assigned.

Some areas, especially western Tasmania, have recorded a shortening of the fire activity period, which may be due to the onset in Epoch 2 of serious wildfire outbreaks in summer, which then dominate the pattern over the span of one or two months. In Epoch 1 this may have been dominated by sporadic lightning ignitions.

\section{PYROCBS}

Another allied dataset that has the potential to show occurrence drift due to climate change is the Australian PyroCb Register (McRae, et al. 2015, Di Virgilio, et al., 2019). Each entry has a date, which can be used to create a map vector in the same manner as those used in the "wind roses" in Figure 1. These can be compared between Epoch 1 and Epoch 2 to look for drift, and also matched against the fire season data (see Figure 4A and Figure 4B ).
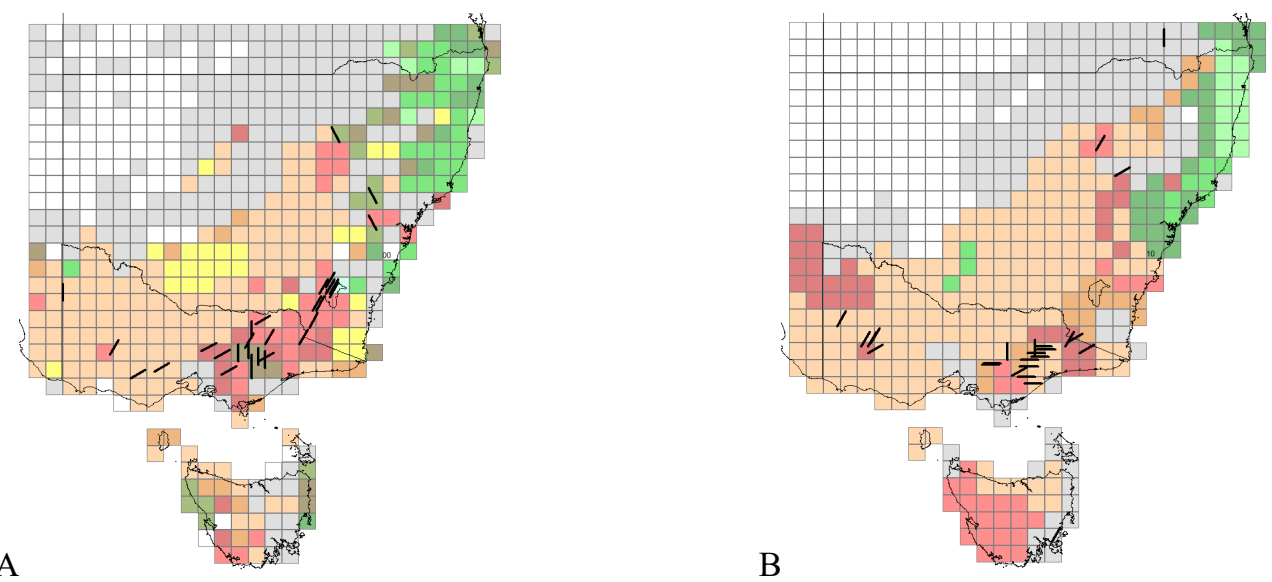

Figure 4. PyroCb occurrence seasonality, from Di Virgilio, et al., 2019. (A) For Epoch 1, month of occurrence (with month number displayed as on a clock-face) of all known pyroCbs in the study domain with peak activity month (as in Figure 2A). (B) For Epoch 2, month of occurrence (with month number displayed as on a clock-face) of all known pyroCbs in the study domain with peak activity month (as in Figure 2B). Note that pyroCbs' vectors are simple to avoid clutter - they are all oriented to between 11 and 3 on a clock-face.

\section{Discussion}

The number of pyroCbs in the register is (fortunately) low. However it is growing rapidly (Di Virgilio, et al., 2019), making it important to assess any trends. Without any quantitative foundation, the following broad assessments may be made:

- From the Hunter Valley to the Pilliga area, pyroCbs are occurring generally 2 to 3 months later in Epoch 2. This is consistent with peak activity data trends. As this trend occurs over a wider area than that affected by pyroCbs, it is likely to be part of the regional trend.

- In the Victorian high country, pyroCbs are occurring 0 to 3 months later in Epoch 2. It is likely that the peak activity trend is largely due to hotspots from pyroCbs, so no additional conclusions are possible here.

- In the Grampians Ranges in western Victoria no change is seen.

- Elsewhere events have only been seen in a single Epoch.

The area northwest of Sydney is a key area to monitor for future trends in pyroCb occurrence and for data to further strengthen any conclusions. 


\section{FROM HERE...}

In the next few years, Epoch 2 may be held constant, with each additional year of data assessed against that. If the trends are consistent then Epoch2 may be expanded to also span 10 years (becoming Epoch $2 b$ ). It is not clear how the dataset will expand when the MODIS data feeds stop. Potentially Himawari-8 data can be aggregated into a form compatible with that from MODIS (especially with respect to data density).

It is to be hoped that this initial analysis will drive an assessment of the separation of wildfire data from prescribed burn data. Without a separation of these two types of fire, it is not possible to analyse trends in the start or end of activity periods for either types of fire. Doing this would be valuable for fire managers, but will require additional analytical tools. Wildfire occurrence may be impacted in a number of ways by climate change, especially in terms of fuel availability and dew point temperature. Prescribed burning patterns may be affected by the same drivers, but also by changing goals of land managers, especially after the damaging fires that create pyroCbs. In this aspect, there may be interconnections that are difficult to detect or quantify.

\section{REFERENCES}

Clarke, H (2015), Climate Change Impacts on Bushfire Risk in NSW. State of NSW and Office of Environment and Heritage.

Clarke, H. \& Evans, J. P. (2018). Exploring the future change space for fire weather in southeast Australia. Theoretical and Applied Climatology, Online First 1-15.

Dowdy, A. J. (2018). Climatological variability of fire weather in Australia. Journal of Applied Meteorology and Climatology 57(2), 221-234.

Dowdy, A.J., Ye, H., Pepler, A., Thatcher, M., Osbrough, S.L., Evans, J.P., Di Virgilio, G. \& McCarthy, N. (2019). Future changes in extreme weather and pyroconvection risk factors for Australian wildfires. Scientific Reports 10073. https://doi.org/10.1038/s41598-019-46362-X.

Di Virgilio, G., Evans, J.P., Blake, S.A.P., Armstrong, M., Dowdy, A.J., Sharples, J. \& McRae, R. (2019). Climate change increases the potential for extreme wildfires. Geophysical Research Letters. https://doi.org/10.1029/2019GL083699.

Giglio, L. (2013). MODIS Collection 5 Active Fire Product User's Guide. Version 2.5. Department of Geographical Sciences, University of Maryland, 61pp.

Harris, S. \& Lucas, C. (2019). Understanding the variability of Australian fire weather between 1973 and 2017.PLoS ONE 14(9):e0222328

Jain P., Wang, X. \& Flannigan, M.D. (2017). Trend analysis of fire season length and extreme fire weather in North America between 1979 and 2015. International Journal of Wildland Fire 26(12) 1009-1020 https://doi.org/10.1071/WF17008

Luke, R.H. \& McArthur, A.G. (1978). Bushfires in Australia. Australian Government Publishing Service, Canberra.

McRae, R. \& Featherston, G. (2015). Modeling Australia's fire seasonality. Proceedings, 2015 MODSIM Conference, Gold Coast.

McRae, R H D, Sharples, JJ \& Fromm, M (2015) Linking local wildfire dynamics to pyroCb development. Natural Hazards and Earth Systems Sciences, 15, 417-428.

Sharples, J.J., Cary, G.J., Fox-Hughes, P. et al. (2016). Natural hazards in Australia: extreme bushfire. Climatic Change, 139, 85-99. https://doi.org/10.1007/s10584-016-1811-1.

Williams, R.J., Bradstock, R.A., Cary, G.J., Enright, N.J., Gill, A.M., Liedloff, A.C., Lucas, C., Whelan, R.J., Andersen, A.N., Bowman, D.M.J.S., Clarke, P.J., Cook, G.D., Hennessy, K.J. \& York, A. (2009). Interactions between climate change, fire regimes and biodiversity in Australia - a preliminary assessment. Report to the Department of Climate Change and Department of the Environment, Water, Heritage and the Arts, Canberra. 